Check for updates

Cite this: RSC Adv., 2018, 8, 20790

Received 3rd February 2018

Accepted 5th May 2018

DOI: $10.1039 / c 8 r a 01069 b$

rsc.li/rsc-advances

\section{Effect of benzoic acid surface modified alumina nanoparticles on the mechanical properties and crystallization behavior of isotactic polypropylene nanocomposites $\dagger$}

\author{
Xiaofeng Jiang, ${ }^{a}$ Wenxue Zhang, ${ }^{\text {b }}$ Shicheng Zhao, ${ }^{a}$ Shuai Zhou, ${ }^{a}$ YaoQi Shi ${ }^{a}$ \\ and Zhong Xin (iD) *a
}

\begin{abstract}
The effect of benzoic acid (BA) surface modified alumina $\left(\mathrm{Al}_{2} \mathrm{O}_{3}\right)$ nanoparticles (NPs) on the mechanical properties and crystallization behavior of isotactic polypropylene (iPP) nanocomposites was studied. Characterization of the modified $\mathrm{Al}_{2} \mathrm{O}_{3} \mathrm{NPs}\left(\mathrm{BA}-\mathrm{Al}_{2} \mathrm{O}_{3}\right)$ by FTIR and XRD analyses confirmed that benzoic acid molecules chemisorb on the surface of the NPs, forming benzene groups-rich microstructures. A considerable increase in the tensile strength, flexural modulus, and toughness was observed for the nanocomposites with only $0.2 \mathrm{wt} \% \mathrm{BA}-\mathrm{Al}_{2} \mathrm{O}_{3}$. Enhanced interfacial adhesion with the matrix was achieved, which enabled effective reinforcement of the nanocomposites. The higher crystallization temperature along with shorter crystallization halftime indicated the higher nucleation activity of BA$\mathrm{Al}_{2} \mathrm{O}_{3}$. Furthermore, the interchain conformational ordering of iPP was significantly accelerated in the presence of the $\mathrm{BA}-\mathrm{Al}_{2} \mathrm{O}_{3} \mathrm{NPs}$. The $\mathrm{CH}-\pi$ interaction between the polymer and $\mathrm{BA}-\mathrm{Al}_{2} \mathrm{O}_{3} \mathrm{NPs}$ was considered to facilitate the attachment of the iPP chains and stimulate conformational ordering, crystallization, as well as mechanical properties of nanocomposites.
\end{abstract}

\section{Introduction}

Isostatic polypropylene (iPP) is one of the most widely used polymers for nanocomposite preparation due to its availability, ease of processing, and relatively low cost. ${ }^{1-3}$ A range of nanoparticles (NPs), such as those of montmorillonite (MMT), ${ }^{4}$ carbon nanotubes (CNTs), ${ }^{5,6}$ graphene, ${ }^{7,8}$ alumina, ${ }^{9}$ and layered double hydroxides (LDH), ${ }^{\mathbf{1 0}, 11}$ has been broadly studied as fillers for nanocomposites. Among the commonly used fillers, alumina $\left(\mathrm{Al}_{2} \mathrm{O}_{3}\right)$ NPs have attracted particular attention due to their good thermal conductivity, high mechanical strength, low cost, and non-toxicity. ${ }^{12,13}$ However, the tendency to form aggregates and the poor dispersion in polymers have detrimental effects on the performance of the resulting nanocomposites. To inhibit unfavorable aggregation and enhance interfacial interactions, surface modification of the NPs has been employed as a useful and flexible strategy in nanocomposite technology. ${ }^{\mathbf{1 4 - 1 6}}$

Extensive research has focused on the surface functionalization of $\mathrm{Al}_{2} \mathrm{O}_{3}$ NPs, such as coating with silane coupling

${ }^{a}$ Shanghai Key Laboratory of Multiphase Materials Chemical Engineering, State-Key Laboratory of Chemical Engineering, East China University of Science and Technology, Shanghai, 200237, China. E-mail: xzh@ecust.edu.cn

${ }^{b}$ Lanzhou Petrochemical Research Center, PetroChina, 730060, China

$\dagger$ Electronic supplementary information (ESI) available. See DOI: $10.1039 / \mathrm{c} 8 \mathrm{ra} 01069 \mathrm{~b}$ agents $^{9,17,18}$ and grafting with polymers. ${ }^{19-21}$ However, the modified $\mathrm{Al}_{2} \mathrm{O}_{3}$ NPs generally have no significant effect on the mechanical performances and crystallization behavior of nonpolar polymer nanocomposites, particularly in low contents. ${ }^{9,20,22-25}$ Zhao and Li studied the crystallization behaviors of nanocomposites containing 1.5-5.0 wt\% of $\mathrm{Al}_{2} \mathrm{O}_{3}$ (pretreated with a silane coupling agent), and the crystallization temperature of the nanocomposites was only enhanced by $4{ }^{\circ} \mathrm{C} .{ }^{9}$ The $\mathrm{Al}_{2} \mathrm{O}_{3}$ NPs are generally surface-modified with hydrocarbon chain structures to improve the compatibility in PP and PE. ${ }^{15,22,26}$ Nonetheless, there is no special interfacial interaction between the PP backbone and the hydrocarbon chain structure of the modified $\mathrm{Al}_{2} \mathrm{O}_{3}$ NPs surface. Theoretical studies have demonstrated that the interfacial interaction between the adsorbing surface and the polymer is important to lower the thermodynamic potential for crystallization. ${ }^{27,28}$ Therefore, the study of functionalization of $\mathrm{Al}_{2} \mathrm{O}_{3}$ NPs with organic groups to generate a special interfacial interaction and subsequently improve the crystallization behavior at a low content is essential.

Recently, some studies have demonstrated that the $\mathrm{CH}-\pi$ interaction has a critical effect on the nucleation and crystallization of polymers. ${ }^{29,30}$ It is believed that this interaction lowers the free energy barrier for nucleation by modulating the segmental motion of the polymer and its subsequent crystallization and growth. ${ }^{29,30}$ However, few studies have focused on the 
functionalization of inorganic NPs with aromatic groups to generate $\mathrm{CH}-\pi$ interactions. Thus, we functionalized $\mathrm{Al}_{2} \mathrm{O}_{3} \mathrm{NPs}$ with aromatic groups to form $\mathrm{CH}-\pi$ interactions with the alkyl groups of the iPP chain. Furthermore, the surface properties of the $\mathrm{Al}_{2} \mathrm{O}_{3}$ NPs could be tuned by different carboxylic acids. ${ }^{31,32} \mathrm{~A}$ few groups have reported the use of these acids as surface modifiers for advanced nanocomposites. ${ }^{33,34}$ Therefore, we investigated the effect of benzoic acid-modified $\mathrm{Al}_{2} \mathrm{O}_{3}$ NPs on the mechanical properties and crystallization behavior of iPP nanocomposites. Through an effective and simple method, aromatic groups-functionalized $\mathrm{Al}_{2} \mathrm{O}_{3}$ NPs were obtained. The specific interactions between iPP and the functionalized NPs improved the properties of the polymer at a low NP content.

Herein, we report the study of the mechanical properties and crystallization behavior of iPP/modified- $\mathrm{Al}_{2} \mathrm{O}_{3}$ nanocomposites. The $\mathrm{Al}_{2} \mathrm{O}_{3}$ NPs were modified with commercially available benzoic acid to tailor the surface chemistry of the NPs. Enhanced flexural, tensile, and impact properties implied the strong interfacial interaction between the iPP matrix and functionalized $\mathrm{Al}_{2} \mathrm{O}_{3}$ NPs $\left(\mathrm{BA}-\mathrm{Al}_{2} \mathrm{O}_{3}\right)$. A remarkable increase in the crystallization temperature was achieved at only $0.2 \mathrm{wt} \% \mathrm{NP}$ content. Furthermore, time-resolved Fourier-transform infrared spectroscopy (FTIR) was employed to follow the intrachain conformation ordering and crystallization evolution of the nanocomposites. The $\mathrm{CH}-\pi$ interaction was considered to facilitate the crystallization behavior and mechanical properties of the $\mathrm{iPP} / \mathrm{BA}-\mathrm{Al}_{2} \mathrm{O}_{3}$ nanocomposites.

\section{Experimental}

\subsection{Materials}

The iPP sample (trade name T30S) was provided by Jiujiang Petroleum Chemical Co., China, with a melt flow rate of $2.9 \mathrm{~g} /$ $10 \min \left(230^{\circ} \mathrm{C} / 2.16 \mathrm{~kg}\right), M_{\mathrm{w}}$ of $24.4 \times 10^{4} \mathrm{~g} \mathrm{~mol}^{-1}$, and $M_{\mathrm{w}} / M_{\mathrm{n}}$ of 4.05. The $\gamma$-alumina $\left(\mathrm{Al}_{2} \mathrm{O}_{3}\right)$ NPs with an average diameter of $10 \mathrm{~nm}$, used in this study, were provided by Adamas Reagent Co., Ltd. Benzoic acid (BA), toluene, and 2-propanol were purchased from Shanghai Lingfeng Chemical Corp. Ethanol was obtained from Shanghai Titan Science Corp. All chemicals were of analytical grade and used without further purification.

\subsection{Synthesis of carboxylate-functionalized nanoparticles}

The functionalization of $\mathrm{Al}_{2} \mathrm{O}_{3}$ NPs is shown in Fig. 1. According to reported procedures, ${ }^{32}$ the alumina nanoparticles $(6 \mathrm{~g})$ were refluxed overnight in toluene $(100 \mathrm{~mL})$ and benzoic acid $(5.27 \mathrm{~g})$. The functionalized particles were then centrifuged for $30 \mathrm{~min}$
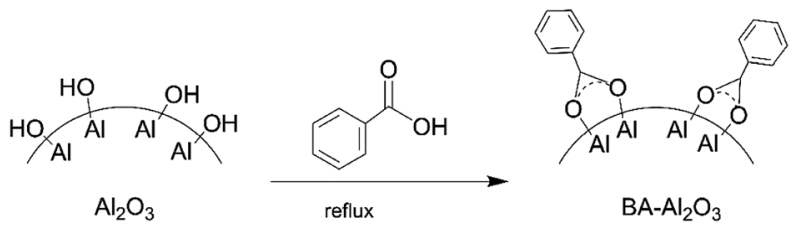

Fig. 1 Schematic diagram of the preparation of functionalized $\mathrm{Al}_{2} \mathrm{O}_{3}$ NPs. and re-dispersed in 2-propanol $(2 \times 30 \mathrm{~mL})$ and ethanol $(1 \times 30$ $\mathrm{mL}$ ), and then centrifuged again to remove unreacted carboxylic acid. Finally, the functionalized NPs $\left(\mathrm{BA}-\mathrm{Al}_{2} \mathrm{O}_{3}\right)$ were oven-dried at $80{ }^{\circ} \mathrm{C}$ overnight.

\subsection{Characterization of nanoparticles}

Fourier-transform infrared (FT-IR) spectroscopy was performed to study the interaction between $\mathrm{BA}$ and $\mathrm{Al}_{2} \mathrm{O}_{3}$ NPs. The FT-IR spectra with a resolution of $4 \mathrm{~cm}^{-1}$ were collected using a Nicolet 5700 FTIR spectrometer with samples in $\mathrm{KBr}$ pellets.

Powder X-ray diffraction (XRD) patterns were recorded on a Bruker advanced D8 powder X-ray diffractometer $(\mathrm{Cu} \mathrm{K} \alpha, \lambda=$ $1.5418 \AA$ A $40 \mathrm{kV}, 40 \mathrm{~mA}$ ). The wide-angle scan ranged from 10$80^{\circ}$ with steps of $0.02^{\circ}$ and $0.1 \mathrm{~s}$ for each step.

Thermogravimetric analysis (TGA) experiments were conducted on a TA Instrument SDT Q600. The samples were run in an open alumina crucible under continuous air flow. The heating profile was equilibrated at $50{ }^{\circ} \mathrm{C}$ and then ramped at $10{ }^{\circ} \mathrm{C} \min ^{-1}$.

\subsection{Nanocomposites preparation}

The nanocomposites were prepared by mixing appropriate amounts of NPs and antioxidant (Irganox 1010 and 168, $0.1 \mathrm{wt} \%$ relative to the iPP powder, respectively), and subsequently melting the blend, followed by the injection-molding of tensile, flexural, and Izod impact bars. In our study, the nanocomposites with pristine $\mathrm{Al}_{2} \mathrm{O}_{3}$ NPs and $\mathrm{BA}-\mathrm{Al}_{2} \mathrm{O}_{3}$ NPs were prepared for comparison. The compound was dry-blended by a high-speed mixer for $5 \mathrm{~min}$. Then, the mixture was extruded by a twin-screw extruder (SJSH-30, Nanjing Rubber and Plastics Machinery Plant Co.) through a strand die and pelletized. The pellets were mold into standard test specimens by an injectionmolding machine (CJ-80E, Guangdong Zhende Plastics Machinery Plant Co.). Standard dumbbell-shaped samples were produced for the tensile property test according to ASTM D-638 (type I). The samples for the flexural property test were rectangular with dimensions of $127 \times 12.7 \times 3.2 \mathrm{~mm}^{3}$ (ASTM D-790). Rectangular samples $\left(63.5 \times 12.7 \times 6.4 \mathrm{~mm}^{3}\right)$ with ' $\mathrm{V}$ ' notches were produced according to ASTM D-256 for the impact strength test. The samples were denoted as $\mathrm{iPP} / \mathrm{BA}-\mathrm{Al}_{2} \mathrm{O}_{3} x$, where ' $x$ ' is the weight percentage of $\mathrm{BA}-\mathrm{Al}_{2} \mathrm{O}_{3}(x \mathrm{wt} \%)$ relative to the weight of the iPP, e.g., iPP/BA- $\mathrm{Al}_{2} \mathrm{O}_{3} 0.2$.

\subsection{Characterization of nanocomposites}

The mechanical properties of the nanocomposites were studied according to the ASTM test methods, such as D-638 for tensile strength and D-790 for flexural modulus, using a universal testing machine (Shanghai D and G Measure Instrument Co.). The Izod impact strength was tested according to D-256 using an impact tester (Chengde Precision Tester Co., model I02.75). The reported values of the mechanical properties were averaged from seven independent measurements.

The DSC measurements of the nanocomposites were carried out on a TA Instruments Q2000 under nitrogen flow, which was calibrated with indium as the standard. For non-isothermal crystallization, the samples (3-5 mg) were first annealed at 
$200{ }^{\circ} \mathrm{C}$ for $5 \mathrm{~min}$ to erase any thermal history and subsequently cooled to $50{ }^{\circ} \mathrm{C}$ at a cooling rate of $20{ }^{\circ} \mathrm{C} \mathrm{min}^{-1}$. Then, the samples were heated to $200{ }^{\circ} \mathrm{C}$ at a rate of $10{ }^{\circ} \mathrm{C} \mathrm{min}^{-1}$. For isothermal crystallization, the samples were annealed at $200{ }^{\circ} \mathrm{C}$ for $5 \mathrm{~min}$ to eliminate the thermal history, cooled to the desired crystallization temperature $\left(T_{\mathrm{C}}\right)$ at a cooling rate of $50{ }^{\circ} \mathrm{C} \mathrm{min}^{-1}$, and maintained at $T_{\mathrm{C}}$ until crystallization was completed. The exothermal plots were recorded for subsequent data analysis.

The morphology studies of the pure iPP and nanocomposites were performed with an Olympus BX51 (Japan) polarized optical microscope (POM) attached with a DP70 digital camera and a THMS600 hot-stage. The extruded samples were placed between two microscopy slides, melted, pressed at $200{ }^{\circ} \mathrm{C}$ for 5 min to remove any trace of crystals, and then cooled to $139{ }^{\circ} \mathrm{C}$ at a cooling rate of $50{ }^{\circ} \mathrm{C} \mathrm{min}{ }^{-1}$ and maintained at $139{ }^{\circ} \mathrm{C}$ until crystallization was completed. Photographs were automatically taken at $1 \mathrm{~min}$ intervals.

The time-resolved FTIR measurements were performed on a Nicolet 5700 FTIR spectrometer (Thermal Scientific, USA) equipped with a heated transmission cell (Mettler FP82 hot stage). The films of pristine iPP and the nanocomposites were deposited on a $\mathrm{KBr}$ pellet to adopt the transmission mode over the wavenumber range of $400-4000 \mathrm{~cm}^{-1}$. The spectra were obtained by averaging 16 scans at resolution of $4 \mathrm{~cm}^{-1}$ with a $30 \mathrm{~s}$ interval and subtracting from the background spectra. Each sample was maintained at $200{ }^{\circ} \mathrm{C}$ for $5 \mathrm{~min}$ to erase any thermal history and cooled to $139{ }^{\circ} \mathrm{C}$ at a rate of $50{ }^{\circ} \mathrm{C} \mathrm{min}{ }^{-1}$. When the temperature reached $139{ }^{\circ} \mathrm{C}$, the data collection started until the end of the crystallization. Herein, the intensity refers to the peak height of the characteristic bands, and the base lines are corrected for each spectrum to the same standard. ${ }^{35}$

\section{Results}

\subsection{Characterization of the modified $\mathrm{Al}_{2} \mathrm{O}_{3}$}

The FTIR spectra of the carboxylic acid-functionalized NPs BA$\mathrm{Al}_{2} \mathrm{O}_{3}$ (Fig. 2) confirm the covalent attachment of the carboxylate moieties. The carbonyl band $(\mathrm{C}=\mathrm{O})$ of the free benzoic acid groups at $1690 \mathrm{~cm}^{-1}$ disappears, indicating the absence of unreacted acid in the products. After surface modification, the new bands at 1400 and $1600 \mathrm{~cm}^{-1}$ are assigned to the symmetric and asymmetric stretching of the carboxylate group $\left(\mathrm{COO}^{-}\right){ }^{33,36}$ It is known from the previous investigations that interactions between carboxylate groups and metal atoms have been classified as monodentate, bridging bidentate, chelating bidentate, and ionic interactions. ${ }^{33,37}$ The relative wavenumber separation $\Delta$ between the asymmetric and symmetric carboxylate stretching bands can be used to distinguish these interactions. $^{33,37}$ The largest $\Delta\left(200-320 \mathrm{~cm}^{-1}\right)$ corresponds to monodentate interactions, and the smallest $\Delta\left(<110 \mathrm{~cm}^{-1}\right)$ corresponds to chelating bidentate interactions. The medium range $\Delta\left(140-190 \mathrm{~cm}^{-1}\right)$ corresponds to bridging bidentate interactions. ${ }^{37}$ In the present study, $\Delta$ has a value of $\sim 130 \mathrm{~cm}^{-1}$ $\left(1566-1438=128 \mathrm{~cm}^{-1}\right)$, suggesting that the interaction between the $\mathrm{COO}$ groups and $\mathrm{Al}$ atoms corresponds to a bridging bidentate bond. Concomitant with these changes is

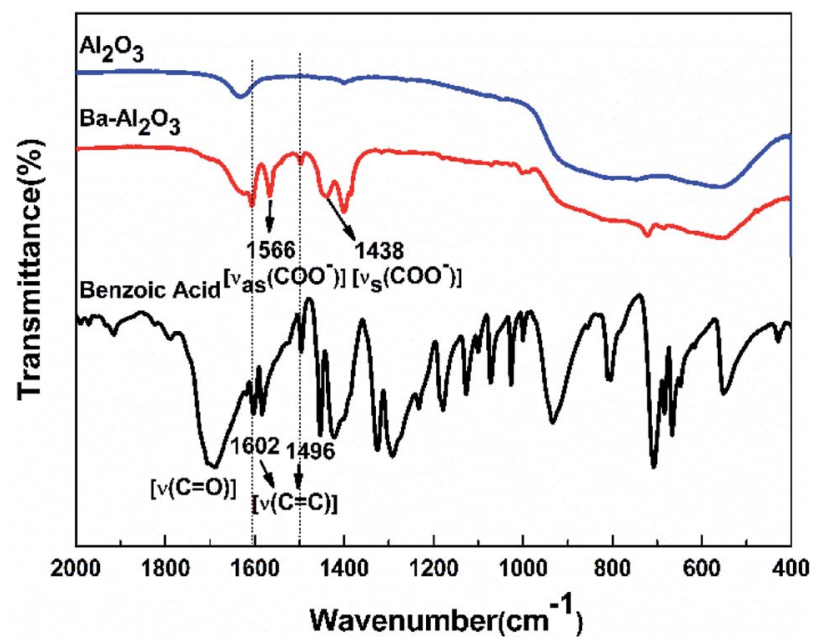

Fig. 2 FTIR spectra of pristine alumina NPs, functionalized alumina NPs, and native carboxylic acids.

the appearance of the peaks at $1602 \mathrm{~cm}^{-1}$ and $1496 \mathrm{~cm}^{-1}$ ascribed to the stretching vibrations of the benzene ring. These data clearly reveal that benzene groups are covalently bonded to the $\mathrm{Al}_{2} \mathrm{O}_{3}$ NPs surface, as shown in Fig. 1 .

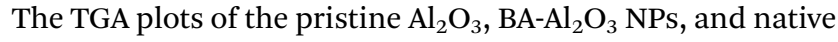
benzoic acid are shown in ESI Fig. S1. $\dagger$ The pristine $\mathrm{Al}_{2} \mathrm{O}_{3} \mathrm{NPS}$ show a weight loss of $\sim 3 \%$ due to degassing and volatilization of water or residual solvents. ${ }^{38}$ Alternatively, in the $200-500{ }^{\circ} \mathrm{C}$ temperature range, the significant weight loss of the $\mathrm{BA}-\mathrm{Al}_{2} \mathrm{O}_{3}$ NPs is attributed to the thermal decomposition of the covalent modifications. It should be mentioned that the extruding and modeling temperature is $200{ }^{\circ} \mathrm{C}$, which is below the decomposition temperature of functionalized alumina. Thus, the BA$\mathrm{Al}_{2} \mathrm{O}_{3}$ NPs will be stable during the decomposition.

A comparison of the crystal structure of $\gamma-\mathrm{Al}_{2} \mathrm{O}_{3}$ before and after surface modification is presented in ESI Fig. S2. $\dagger$ In this profile, $(311)$ at $2 \theta=37.6^{\circ},(400)$ at $45.9^{\circ}$, and $(440)$ at $67.0^{\circ}$ are the principal reflections of $\gamma-\mathrm{Al}_{2} \mathrm{O}_{3}$. As shown in the figure, the peak position of the crystal plane does not shift after reaction with benzoic acid. This indicates that the typical pattern of $\gamma$ $\mathrm{Al}_{2} \mathrm{O}_{3}$ is not affected by the addition of carboxylic acid. We can suppose that the benzoic acid molecules are only chemisorbed on the surface of the NPs and are covalently attached on the surface, which does not change the crystal structure.

\subsection{Mechanical properties of the nanocomposites}

From the perspective of industrial application, it is important to investigate the effect of NPs on the mechanical properties of the nanocomposites. Fig. 3 shows the comparison of the influence of $\mathrm{Al}_{2} \mathrm{O}_{3}$ and $\mathrm{BA}-\mathrm{Al}_{2} \mathrm{O}_{3}$ on the mechanical properties of the iPP nanocomposites. The addition of $\mathrm{Al}_{2} \mathrm{O}_{3}$ slightly improved the tensile strength and flexural modulus. However, the introduction of $\mathrm{BA}-\mathrm{Al}_{2} \mathrm{O}_{3}$ causes a greater improvement in the tensile strength, flexural modulus, and Izod impact strength as compared to pristine $\mathrm{Al}_{2} \mathrm{O}_{3}$. The flexural modulus is increased by about $13.2 \%$ in the case of the as-received $\mathrm{Al}_{2} \mathrm{O}_{3}$ at content of 


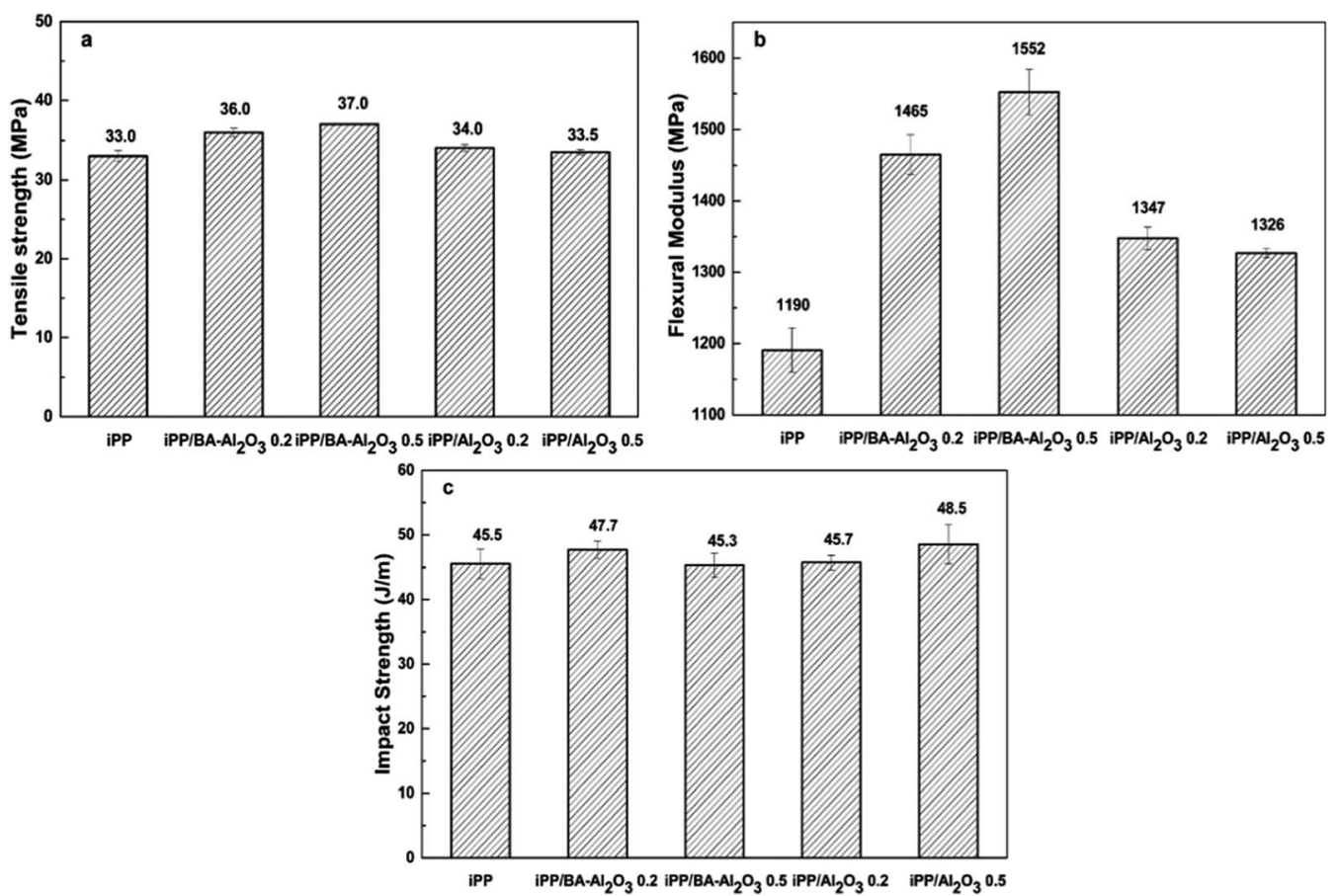

Fig. 3 Influence of different nanoparticles on the (a) tensile strength, (b) flexural modulus, and (c) impact strength of iPP.

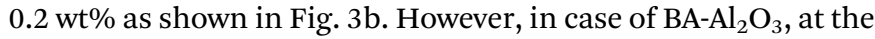
same content of $0.2 \mathrm{wt} \%$, the flexural modulus significantly improved by about $23.1 \%$. The enhancement in the mechanical properties of the iPP/BA- $\mathrm{Al}_{2} \mathrm{O}_{3}$ nanocomposite is observed, which can be attributed to the improved interactions between iPP and $\mathrm{BA}-\mathrm{Al}_{2} \mathrm{O}_{3}$ NPs.

Fig. 4 and ESI Table $\mathrm{S} 1 \dagger$ present the mechanical properties of the iPP/BA- $\mathrm{Al}_{2} \mathrm{O}_{3}$ nanocomposites as a function of NPs content. An initial increase in stiffness at low NPs concentrations can be distinguished, which remains constant with the increase in NPS content. An increase of $11.4 \%$ in tensile strength and an increase of $19.1 \%$ in flexural modulus were achieved in the iPP nucleated by $0.025 \mathrm{wt} \% \mathrm{BA}-\mathrm{Al}_{2} \mathrm{O}_{3}$. When the content of $\mathrm{BA}-\mathrm{Al}_{2} \mathrm{O}_{3}$ is $0.2 \mathrm{wt} \%$, the tensile strength and flexural modulus of the nucleated iPP improved by about $16.2 \%$ and $32.0 \%$, respectively, compared with that of pure iPP. Generally, the toughness will show a trend opposing that of the stiffness. However, a great enhancement of more than $20 \%$ of the impact strength of the nanocomposites is obtained upon the incorporation of $0.1 \mathrm{wt} \% \mathrm{BA}^{-} \mathrm{Al}_{2} \mathrm{O}_{3}$. At higher $\mathrm{BA}-\mathrm{Al}_{2} \mathrm{O}_{3}$ concentrations, this increase progressively plateaus, but remains higher than that of neat iPP. From these experimental results, it can be concluded that the presence of $\mathrm{BA}-\mathrm{Al}_{2} \mathrm{O}_{3}$ has a significant impact on the mechanical performance and maintains a good balance between the stiffness and toughness of iPP nanocomposites.

\subsection{Effects of interfacial interactions on the mechanical properties of iPP/BA- $\mathrm{Al}_{2} \mathrm{O}_{3}$ nanocomposites}

It is known that the interfacial interaction is of great significance in determining the properties of nanocomposites. In general, poor interactions between the NPs and the polymer matrix in nanocomposites will introduce artificial defects, which consequently result in a negative effect on the mechanical properties. ${ }^{39}$ Therefore, investigating the interfacial interactions between iPP and $\mathrm{BA}-\mathrm{Al}_{2} \mathrm{O}_{3}$ is considered crucial as the nanocomposites exhibit excellent mechanical properties. The interfacial adhesion between the matrix and the dispersed NPs can be determined by applying the famous Einstein equation, as shown in eqn (1): ${ }^{\mathbf{4 0 , 4 1}}$

$$
E_{\mathrm{c}} / E_{\mathrm{m}}=\left(1+B V_{\mathrm{f}}\right)
$$

where $E_{\mathrm{c}}$ and $E_{\mathrm{m}}$ are the elastic moduli of the composite and the polymer matrix, respectively. $B$ is the parameter characterizing the interfacial adhesion. $V_{\mathrm{f}}$ is the volume fraction of NPs in the nanocomposites, which can be calculated using eqn (2):

$$
V_{\mathrm{f}}=\rho_{\mathrm{m}} W_{\mathrm{f}} /\left[\left(\rho_{\mathrm{m}}-\rho_{\mathrm{f}}\right) W_{\mathrm{f}}+\rho_{\mathrm{f}}\right]
$$

where $W_{\mathrm{f}}$ is the weight fraction of NPs, $\rho_{\mathrm{m}}$ is the density of iPP $\left(0.92 \mathrm{~g} \mathrm{~cm}^{-3}\right)$, and $\rho_{\mathrm{f}}$ is the density of the $\mathrm{Al}_{2} \mathrm{O}_{3}$ NPs $\left(3.97 \mathrm{~g} \mathrm{~cm}^{-3}\right)$.

If there is no adhesion between the matrix and the NPs, $B$ becomes 1 , while for strong adhesion, $B$ takes values higher than 2.5. In Fig. 5, the variation of the relative elastic modulus (see ESI Table $\mathrm{S} 1 \dagger$ ) and adhesion parameter $B$ (calculated from eqn (1)) with the $\mathrm{BA}-\mathrm{Al}_{2} \mathrm{O}_{3}$ NPs content is illustrated. It can be seen clearly that the constant $B$ is much higher than 2.5 for the low NPs concentration of $0.025 \mathrm{wt} \%$, indicating that the adhesion between iPP and $\mathrm{BA}-\mathrm{Al}_{2} \mathrm{O}_{3}$ is very strong. The low-filled nanocomposites have better dispersed NPs aggregates, which indicates that larger surface is available to contribute to better adhesion. ${ }^{41}$ The parameter decreases as the NPs loading 

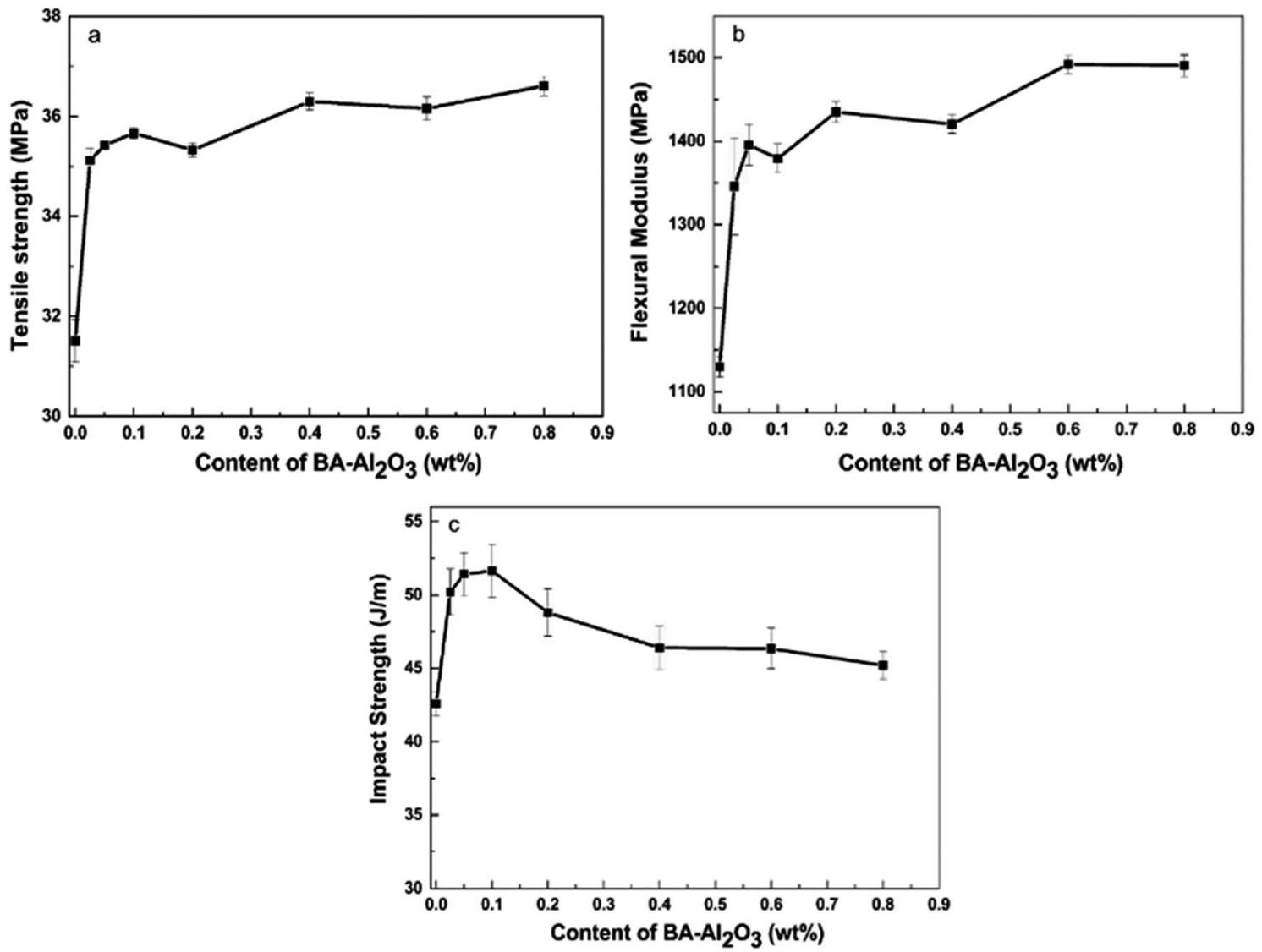

Fig. 4 Effects of the mass fraction of $\mathrm{BA}-\mathrm{Al}_{2} \mathrm{O}_{3}$ NPs on the (a) tensile strength, (b) flexural modulus, and (c) impact strength of iPP.

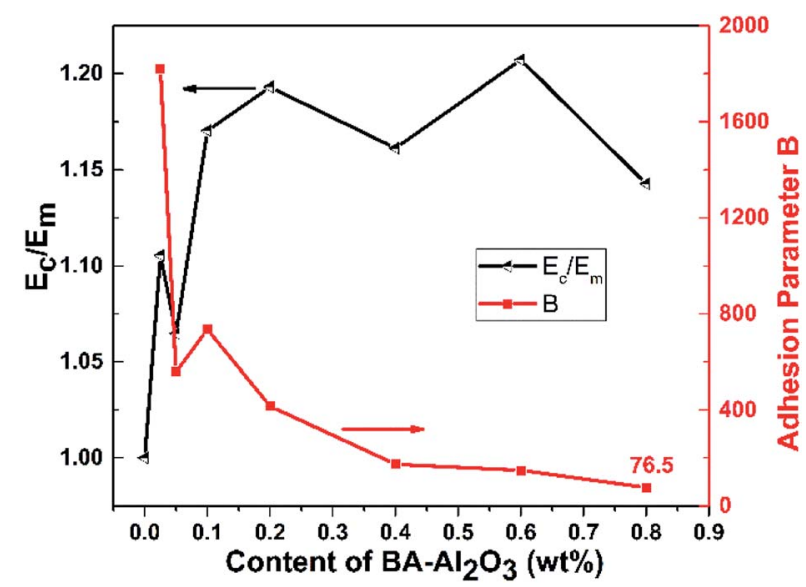

Fig. 5 Variation of the relative elastic modulus and adhesion parameter $\mathrm{B}$ as a function of $\mathrm{BA}-\mathrm{Al}_{2} \mathrm{O}_{3} \mathrm{NP}$ content.

increases, suggesting that aggregation leads to the decrease in the available surface of the $\mathrm{BA}-\mathrm{Al}_{2} \mathrm{O}_{3} \mathrm{NPs}$, which prevents good adhesion. However, it is noted that though the adhesion is poorer at high NPs content, the adhesion parameter is still much higher than 2.5, suggesting that the interfacial adhesion is very strong.

The noteworthy interfacial adhesion observed in the nanocomposites with low NPs content can be attributed to the special interfacial interactions. In the present study, the $\mathrm{CH}-\pi$ interaction between the methyl groups group of iPP and the benzene rings of $\mathrm{BA}-\mathrm{Al}_{2} \mathrm{O}_{3}$ may play an important role in linking the nanoparticle surface and the polypropylene matrix. This linkage allows the nanocomposites to behave like a unit, in which the robust NPs make the polymer stronger, which is consistent with the fact that good interfacial interaction has a significant effect on the mechanical properties. ${ }^{17}$ Therefore, compared with the as-received $\mathrm{Al}_{2} \mathrm{O}_{3}$ NPs, the simply modified interphase could exhibit higher stiffness and toughness.

\subsection{Crystallization behaviors of the nanocomposites}

As the nanocomposites exhibit strong interfacial interaction, the effect of the interfacial interaction on the crystallization behavior was also investigated. The crystallization temperature $\left(T_{\mathrm{C}}\right)$ is a measure of the crystallization behavior of the polymer upon cooling from the melt. The higher $T_{\mathrm{C}}$ value suggests higher nucleation efficiency and faster crystallization rate and even shorter progressing times. Fig. 6a shows the DSC heat flow curves of neat iPP and the $\mathrm{iPP} / \mathrm{Al}_{2} \mathrm{O}_{3}$ and iPP/BA- $\mathrm{Al}_{2} \mathrm{O}_{3}$ nanocomposites at $0.2 \mathrm{wt} \%$ and $0.5 \mathrm{wt} \%$ loading during cooling at a cooling rate of $20{ }^{\circ} \mathrm{C} \mathrm{min}^{-1}$. It is evident from the $T_{\mathrm{C}}$ values that there is slight improvement upon the incorporation of $0.2 \mathrm{wt} \%$ pristine $\mathrm{Al}_{2} \mathrm{O}_{3}$ NPs. With the increase in $\mathrm{Al}_{2} \mathrm{O}_{3}$ NPs content, lower peak temperature is observed. With the addition 

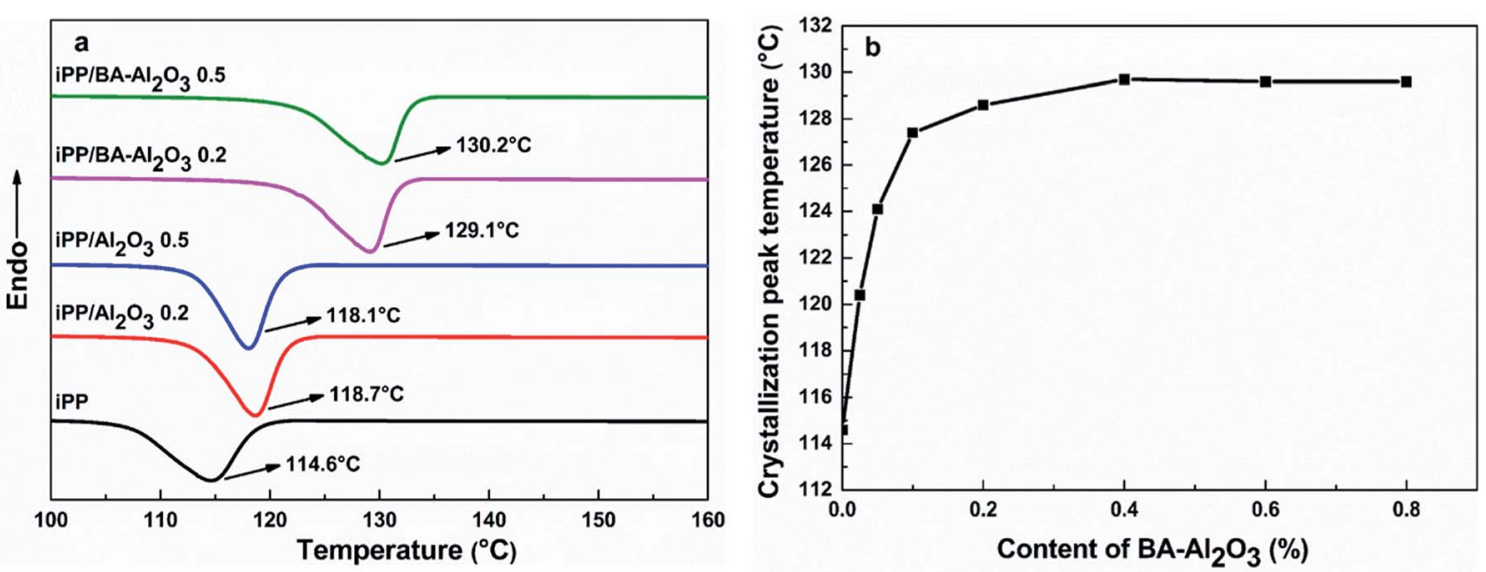

Fig. 6 (a) DSC heat flow curves during cooling at a cooling rate of $20{ }^{\circ} \mathrm{C} \mathrm{min}-1$ for neat iPP and iPP/Al $\mathrm{O}_{3}$ and iPP/BA-Al $\mathrm{O}_{3}$ nanocomposites at a $0.2 \mathrm{wt} \%$ and $0.5 \mathrm{wt} \% \mathrm{NP}$ loading. (b) Effects of $\mathrm{BA}-\mathrm{Al}_{2} \mathrm{O}_{3}$ content on the crystallization behavior of iPP revealed by DSC at a cooling rate of $20{ }^{\circ} \mathrm{C} \mathrm{min}^{-1}$.

of only $0.2 \mathrm{wt} \% \mathrm{BA}-\mathrm{Al}_{2} \mathrm{O}_{3} \mathrm{NPs}$, the $T_{\mathrm{C}}$ of the $\mathrm{iPP} / \mathrm{BA}-\mathrm{Al}_{2} \mathrm{O}_{3}$ nanocomposites shows a remarkable increase of $\sim 15{ }^{\circ} \mathrm{C}$ compared to pure iPP, which is comparable to an increase of $\sim 10{ }^{\circ} \mathrm{C}$ for pristine $\mathrm{iPP} / \mathrm{Al}_{2} \mathrm{O}_{3}$. Comparison of the nanocomposites at equal NPs loading permits further consideration of the changes in the nucleation ability of the $\mathrm{Al}_{2} \mathrm{O}_{3}$ NPs upon surface modification. These changes can be correlated with changes in the polymer-NPs interfacial interactions. ${ }^{38}$ The enhanced nucleation effects at such low content is not observed in many iPP nanocomposites containing functionalized $\mathrm{Al}_{2} \mathrm{O}_{3}$ $\mathrm{NPs},{ }^{9,23}$ which can be attributed to the special interfacial interaction between iPP and $\mathrm{BA}-\mathrm{Al}_{2} \mathrm{O}_{3}$ NPs.

Fig. $6 \mathrm{~b}$ shows the effect of the $\mathrm{BA}-\mathrm{Al}_{2} \mathrm{O}_{3}$ content on the nonisothermal crystallization behavior under a cooling rate of $20{ }^{\circ} \mathrm{C} \min ^{-1}$. It can be seen that compared to pure iPP, the

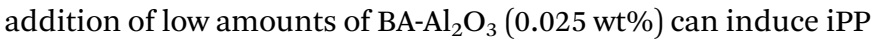
crystallization at higher temperature, suggesting that the addition of $\mathrm{BA}-\mathrm{Al}_{2} \mathrm{O}_{3}$ apparently accelerates the crystallization of iPP due to strong heterogeneous nucleation effect in the

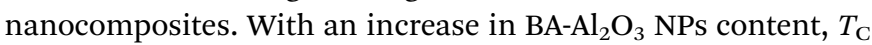
significantly increases as expected. Moreover, the iPP with $0.2 \mathrm{wt} \% \mathrm{BA}^{-\mathrm{Al}_{2} \mathrm{O}_{3}}$ exhibits the greatest enhancement in $T_{\mathrm{C}}$ of nearly $14{ }^{\circ} \mathrm{C}$. Further increase in the $\mathrm{BA}-\mathrm{Al}_{2} \mathrm{O}_{3}$ NPs content can result in a slight improvement in the iPP crystallization ability, and a slight reduction in $T_{\mathrm{C}}$ eventually occurs when the BA$\mathrm{Al}_{2} \mathrm{O}_{3}$ NPs content increases to $0.6 \mathrm{wt} \%$ and $0.8 \mathrm{wt} \%$. The phenomenon of saturation concentration could be attributed to the decrease in the effective concentration resulting from the agglomeration of additives at high loadings. ${ }^{42,43}$ The addition of BA- $\mathrm{Al}_{2} \mathrm{O}_{3}$ NPs shows two types of effects on the crystallization

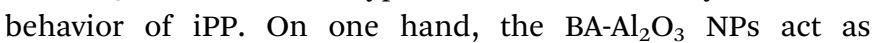
a heterogeneous nucleating agent to increase the crystallization nucleation rate. On the other hand, the addition of higher amounts of $\mathrm{BA}-\mathrm{Al}_{2} \mathrm{O}_{3}$ NPs can induce topological confinement effects that can eventually lead to the deterioration of nucleation and crystallization kinetics. ${ }^{40}$ The DSC heat flow curves of the nanocomposites during heating at a rate of $10{ }^{\circ} \mathrm{C} \mathrm{min}^{-1}$ are presented in ESI Fig. S3 and S4. $\dagger$ All nanocomposites show only one melting peak of $165^{\circ} \mathrm{C}$, which is the characteristic melting temperature of the $\alpha$-phase of PP. It is clear that the addition of $\mathrm{Al}_{2} \mathrm{O}_{3}$ or $\mathrm{BA}-\mathrm{Al}_{2} \mathrm{O}_{3}$ does not change the crystal form of iPP.

Fig. 7 further shows the changes in the crystallization halftime $t_{1 / 2}$ of neat iPP and the $\mathrm{iPP} / \mathrm{Al}_{2} \mathrm{O}_{3}$ and $\mathrm{iPP} / \mathrm{BA}-\mathrm{Al}_{2} \mathrm{O}_{3}$ nanocomposites at $0.2 \mathrm{wt} \%$ and $0.5 \mathrm{wt} \%$ NPs content under isothermal crystallization at different temperatures. The $t_{1 / 2}$ can be extracted from the DSC measurements to characterize the crystallization rate. It is evident that $t_{1 / 2}$ greatly decreases with the addition of NPs for all nanocomposites, reflecting an enhancement in the crystallization rate of iPP. In addition, shorter $t_{1 / 2}$ at low crystallization temperatures suggests that the nucleating effect is more significant with decreasing crystallization temperature. However, remarkable differences can be observed in the crystallization rate of nanocomposites containing pristine and functionalized $\mathrm{Al}_{2} \mathrm{O}_{3}$ NPs. When the asreceived $\mathrm{Al}_{2} \mathrm{O}_{3}$ was added into iPP, the $t_{1 / 2}$ decreased

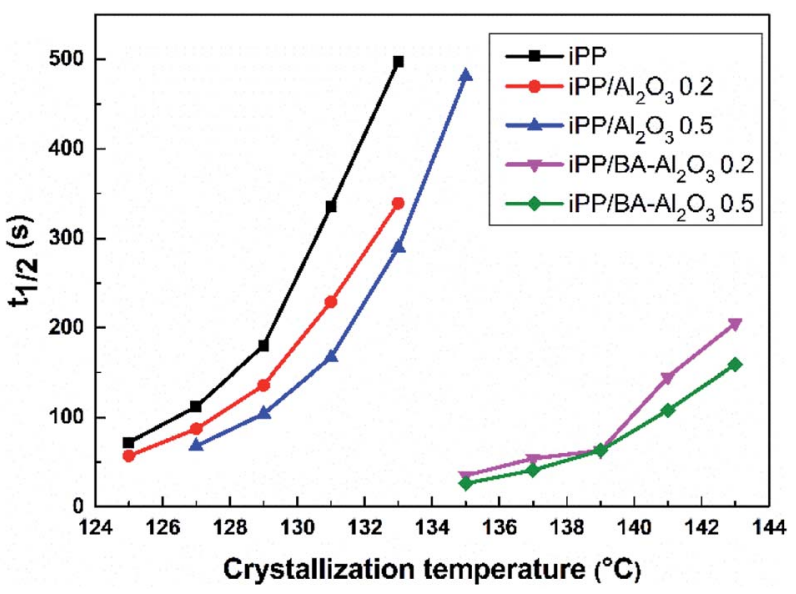

Fig. $7 t_{1 / 2}$ of neat iPP, and $i \mathrm{PP} / \mathrm{Al}_{2} \mathrm{O}_{3}$ and iPP/BA- $\mathrm{Al}_{2} \mathrm{O}_{3}$ nanocomposites at $0.2 \mathrm{wt} \%$ and $0.5 \mathrm{wt} \%$ NPs loading under isothermal crystallization at different temperatures. 
moderately with the increase in $\mathrm{Al}_{2} \mathrm{O}_{3}$ content. The $t_{1 / 2}$ at $131{ }^{\circ} \mathrm{C}$ decreases from $5.6 \mathrm{~min}$ for pure iPP to $3.8 \mathrm{~min}$ and $2.8 \mathrm{~min}$ with $0.2 \mathrm{wt} \%$ and $0.5 \mathrm{wt} \% \mathrm{Al}_{2} \mathrm{O}_{3}$, respectively. On the other hand, the acceleration of the crystallization rate upon addition of $0.2 \mathrm{wt} \%$ $\mathrm{BA}-\mathrm{Al}_{2} \mathrm{O}_{3}$ is prominent. The $t_{1 / 2}$ decreases to $0.9 \mathrm{~min}$ with $0.2 \mathrm{wt} \% \mathrm{BA}-\mathrm{Al}_{2} \mathrm{O}_{3}$ at $139{ }^{\circ} \mathrm{C}$, whereas the neat iPP and $\mathrm{iPP} / \mathrm{Al}_{2} \mathrm{O}_{3}$ nanocomposites have much longer $t_{1 / 2}$ values. As can be clearly seen, the functionalized alumina NPs can promote the crystallization of iPP at much higher temperatures, such as $143{ }^{\circ} \mathrm{C}$, and the crystallization can be completed within $3 \mathrm{~min}$.

The morphological evolution of the neat iPP and nanocomposites with $0.2 \mathrm{wt} \%$ content during isothermal crystallization at $139{ }^{\circ} \mathrm{C}$ is revealed by POM photomicrographs, as shown in Fig. 8. The neat iPP exhibits several large spherulites with an average diameter of $\sim 80 \mu \mathrm{m}$ after $60 \mathrm{~min}$ (Fig. 8a). Upon addition of $\mathrm{Al}_{2} \mathrm{O}_{3}$, the sample (Fig. 8b) exhibited higher nucleation densities (more nuclei) than neat iPP (Fig. 8a) as the crystallization proceeds. The crystallization of iPP/ $/ \mathrm{Al}_{2} \mathrm{O}_{3}$ was almost complete after $50 \mathrm{~min}$ with smaller spherulites size (Fig. 8b). With the addition of $\mathrm{BA}-\mathrm{Al}_{2} \mathrm{O}_{3}$, the nucleation density increased and the diameter of the spherulites decreased significantly (Fig. 8c). Moreover, the crystallization of the iPP/ BA- $\mathrm{Al}_{2} \mathrm{O}_{3}$ nanocomposites was completed in only $3 \mathrm{~min}$ (Fig. 8c). It is clear that highly dispersed NPs act as nucleation sites and subsequently accelerate the iPP spherulite growth. With an increase in nuclei density, the spherulites tended to impinge on their neighbors to stop further growth, resulting in smaller spherulites.

Overall, the improvement of the nucleation density observed by POM can be correlated to the acceleration of crystallization, as evidenced by DSC (Fig. 6 and 7). In addition, the sufficient consistency suggests that the $\mathrm{CH}-\pi$ interactions between the polymer and surface of the $\mathrm{BA}-\mathrm{Al}_{2} \mathrm{O}_{3}$ NPs contribute greatly to the acceleration of the crystallization rate of $\mathrm{iPP} / \mathrm{BA}-\mathrm{Al}_{2} \mathrm{O}_{3}$ nanocomposites. Due to the distinct interaction, which may cause the iPP chains to crystallize, the functionalized NPs exhibit more efficient nucleation ability than the pristine $\mathrm{Al}_{2} \mathrm{O}_{3}$ NPs.

\subsection{Effects on the intrachain conformational ordering}

After observing the difference in the nucleation ability of $\mathrm{Al}_{2} \mathrm{O}_{3}$ and $\mathrm{BA}-\mathrm{Al}_{2} \mathrm{O}_{3}$, attention was focused on the effect of the interfacial interaction on the physical origin of the strong inducing efficiency of $\mathrm{BA}-\mathrm{Al}_{2} \mathrm{O}_{3}$ for iPP crystallization. Till date, different theoretical models have been proposed to describe the progress of polymer crystallization. ${ }^{44-46}$ It is commonly agreed that conformational ordering plays a critical role during this complex process. The molecular chains need to undergo conformational ordering while the persistence length of the helical sequences of the polymer increases before crystallization. ${ }^{45}$ When the length exceeds the critical length, the $3_{1}$ helical conformation begins to congregate, following which

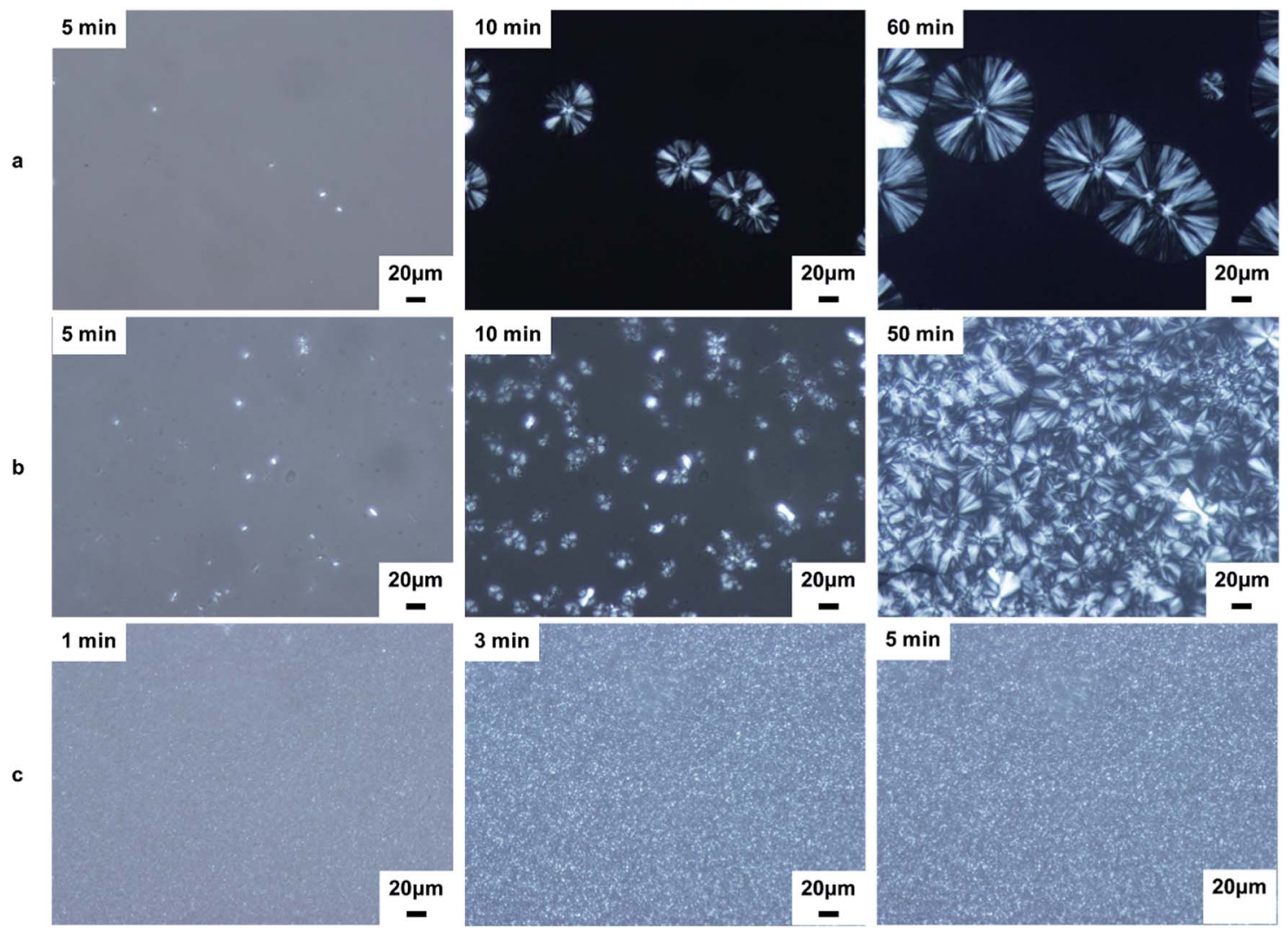

Fig. 8 POM micrographs of neat iPP and nanocomposites crystallized during isothermal crystallization at $139{ }^{\circ} \mathrm{C}(\mathrm{a}) \mathrm{iPP} ;(\mathrm{b}) \mathrm{iPP} / \mathrm{Al}{ }_{2} \mathrm{O}_{3} 0.2 ;(\mathrm{c}) \mathrm{iPP} /$ $\mathrm{BA}-\mathrm{Al}_{2} \mathrm{O}_{3} 0.2$. 

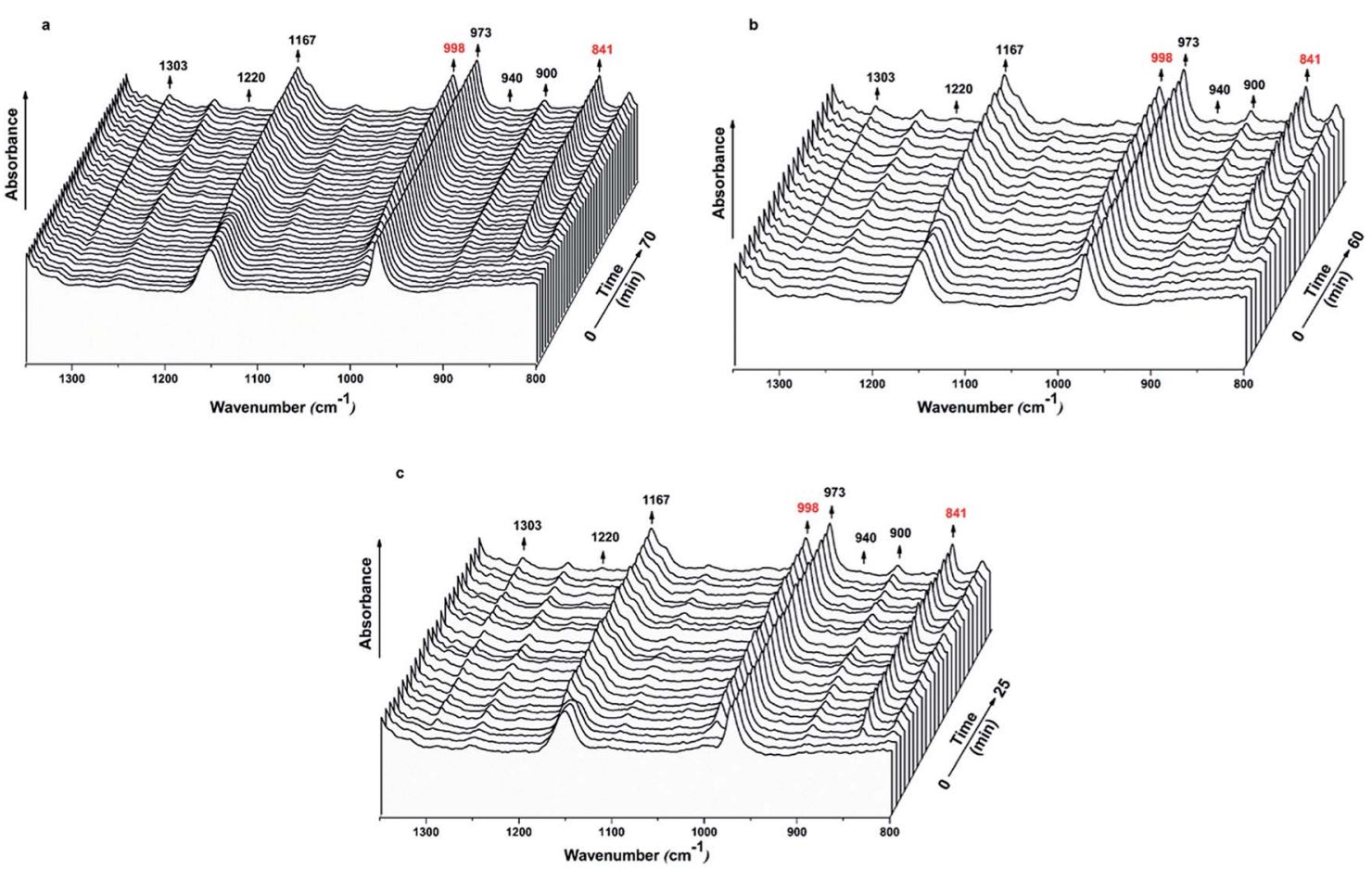

Fig. 9 Time-resolved spectra in the $1350-800 \mathrm{~cm}^{-1}$ range of (a) iPP, (b) iPP/Al${ }_{2} \mathrm{O}_{3} \quad 0.2$, and (c) iPP/BA- $\mathrm{Al}_{2} \mathrm{O}_{3} 0.2$ isothermally $\mathrm{crystallizing}$ at $139^{\circ} \mathrm{C}$

crystallization is induced. Therefore, tracing the intrachain conformational ordering is the best approach to obtain deep insight in the interfacial interaction effect on $\mathrm{BA}^{-} \mathrm{Al}_{2} \mathrm{O}_{3}$-driven iPP crystallization. ${ }^{35}$ FTIR is highly sensitive to conformation changes and packing density of molecular chains and was thus used to investigate the crystallization process of the iPP/BA$\mathrm{Al}_{2} \mathrm{O}_{3}$ nanocomposites.

Fig. 9 reveals the time-resolved FTIR spectra of iPP, $i \mathrm{PP} / \mathrm{Al}_{2} \mathrm{O}_{3}$ 0.2 , and $\mathrm{iPP} / \mathrm{BA}^{-} \mathrm{Al}_{2} \mathrm{O}_{3} 0.2$ isothermally crystallizing at $139{ }^{\circ} \mathrm{C}$. The intensity of the regularity bands changes as the time increases. The IR bands at 940, 1220, 1303, 1167, 841, 998, 900, and $973 \mathrm{~cm}^{-1}$ correspond to the $3_{1}$ helical structures with decreasing degrees of order. ${ }^{47}$ Because different helical lengths show different IR absorption bands, the gain in conformational ordering bands is directly attributed to the augmentation of the helical population. ${ }^{48,49}$ As shown in Fig. 9, short helical structures already exist in the iPP melt, as evidenced by the strong peak at $973 \mathrm{~cm}^{-1}$ (helical length with 3-4 monomers). These short helices undergo propagation and incorporation ${ }^{50}$ to form longer helices. Therefore, the intensity of other IR bands corresponding to long helices also increases with time.

According to the Doi-Edwards's dynamics theory, the critical persistence length of iPP for crystallization transition is 11 monomers in the $3_{1}$ helical conformation. ${ }^{47}$ The conformational band at $998 \mathrm{~cm}^{-1}$ corresponds to 10 monomer units, which is suggested to be more sensitive to the stable-to-unstable transition when crystallization is triggered. ${ }^{35}$ The $998 \mathrm{~cm}^{-1}$ band is reasonably chosen to analyse the conformation evolution during crystallization, and the $841 \mathrm{~cm}^{-1}$ band corresponding to the helical length with 12 monomers is taken as the crystalline signal. ${ }^{35,45}$ The evolution of the two regular bands may help understand the crystallization process and particularly determine how $\mathrm{BA}-\mathrm{Al}_{2} \mathrm{O}_{3}$ accelerates iPP crystallization at the early stages.

Fig. 10a illustrates the normalized intensity of the crystalline band (I841) as a function of crystallization time for iPP and its nanocomposites. The crystallization of iPP is slightly accelerated in the presence of $0.2 \mathrm{wt} \% \mathrm{Al}_{2} \mathrm{O}_{3}$, which is consistent with

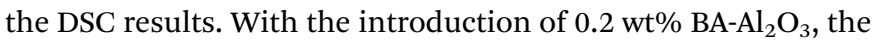
$t_{1 / 2}$ of the $\mathrm{iPP} / \mathrm{BA}-\mathrm{Al}_{2} \mathrm{O}_{3} 0.2$ nanocomposites decreases from 20.3 to $2.5 \mathrm{~min}$. Interestingly, the corresponding variations in the conformational ordering bands follow the same trend as that

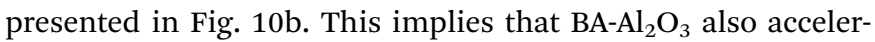
ates the conformational ordering of iPP, which is associated with an acceleration of crystallization. The in situ FTIR results provided deeper insight in $\mathrm{BA}_{-} \mathrm{Al}_{2} \mathrm{O}_{3}$-driven polymer crystallization by establishing a relationship with the $\mathrm{BA}-\mathrm{Al}_{2} \mathrm{O}_{3}$ induced
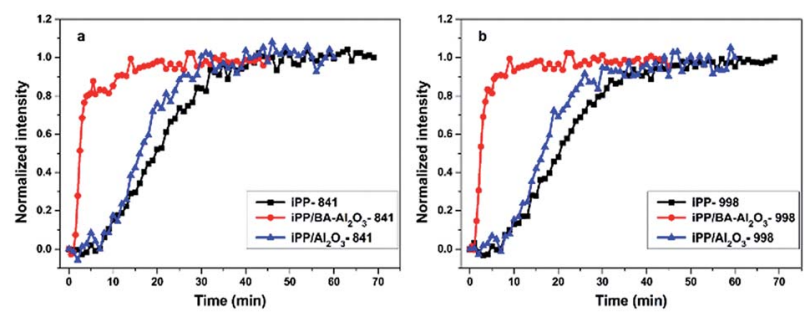

Fig. 10 Normalized intensity of the (a) crystalline band at $841 \mathrm{~cm}^{-1}$ and (b) conformational ordering band at $998 \mathrm{~cm}^{-1}$ as a function of time for iPP, iPP/Al $\mathrm{O}_{3} 0.2$, and iPP/BA- $\mathrm{Al}_{2} \mathrm{O}_{3} 0.2$ isothermally crystallizing at $139{ }^{\circ} \mathrm{C}$. 


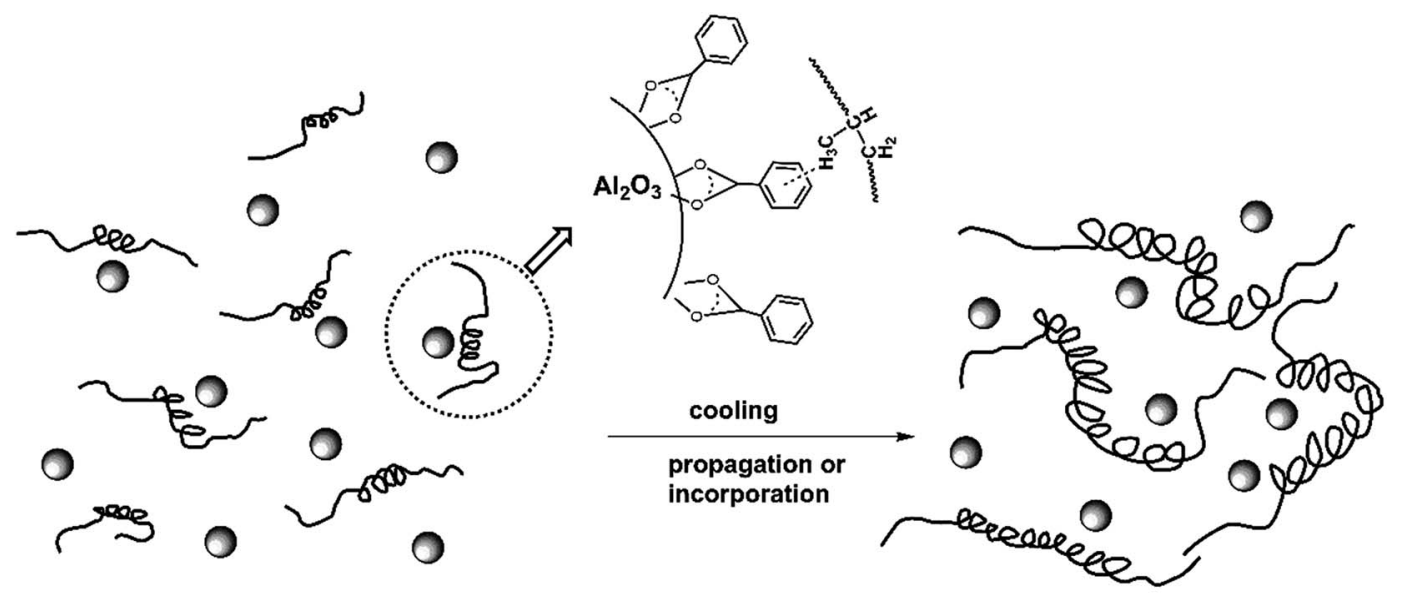

$\mathrm{BA}-\mathrm{Al}_{2} \mathrm{O}_{3}$

กeer PP helices

Fig. 11 Schematic diagram of intrachain conformation ordering in iPP induced by the $\mathrm{CH}-\pi$ interaction between the polymer and $\mathrm{BA}-\mathrm{Al}_{2} \mathrm{O}_{3}$.

conformation ordering. Upon addition of $\mathrm{BA}-\mathrm{Al}_{2} \mathrm{O}_{3}$, the short helical segments tend to propagate or incorporate to form long helical segments due to the interfacial interactions between the NPs surface and the polymer.

\section{Discussions}

The experimental results clearly demonstrate that the benzoic acid functionalized alumina NPs $\left(\mathrm{BA}-\mathrm{Al}_{2} \mathrm{O}_{3} \mathrm{NPs}\right)$ can enhance both the mechanical performance and the crystallization behavior. The reaction of benzoic acid with alumina NPs did not change the crystal structure (see ESI Fig. S2 $\dagger$ ). The NPs surfaces were covalently bonded to benzene rings after functionalization. Thus, it is supposed that special interactions are formed between the polymer and the benzene rings of $\mathrm{BA}-\mathrm{Al}_{2} \mathrm{O}_{3}$.

The $\mathrm{CH}-\pi$ interaction between carbon-hydrogen groups $(\mathrm{CH}$ groups) and $\pi$-systems has been known for many years. Although the strength of the $\mathrm{CH}-\pi$ interaction is only one-tenth of a hydrogen bond, the interaction still remarkably influences polymer nanocomposites. ${ }^{29,30,51-53}$ Considering the aromatic rings as $\pi$-systems and iPP as 'CH-rich' polymers, $\mathrm{CH}-\pi$ interactions should occur between $\mathrm{BA}^{-} \mathrm{Al}_{2} \mathrm{O}_{3}$ and iPP, which improves the conformational ordering and crystallization kinetics as well as the mechanical properties.

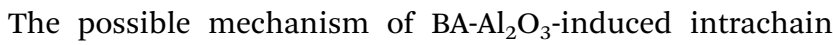
conformational ordering is schematically illustrated in Fig. 11. At the initial stage of crystallization, the short helices tend to adsorb on the surface of $\mathrm{BA}-\mathrm{Al}_{2} \mathrm{O}_{3}$ via $\mathrm{CH}-\pi$ interactions, as presented in Fig. 11. It should be mentioned that the interactions occur between the protruding methyl groups and the aromatic rings.

Another study also suggested that intrachain conformational ordering is enhanced by the interaction between the protruding methyl groups of iPP and graphene layers of $\mathrm{sp}^{2}$-bonded carbon. ${ }^{54}$ These specific type of $\mathrm{CH}-\pi$ interaction has not yet been proved experimentally. Short helices undergo propagation and incorporation to form long helical segments during the cooling process. ${ }^{50}$ Then, the preexisting long helices pack into the formed coupled helices, thus significantly accelerating crystallization (see Fig. 11).

In summary, $\mathrm{CH}-\pi$ interaction plays a critical role in reducing the free energy barriers of nucleation and subsequent crystallization and growth. The mechanical properties are believed to be affected by this interaction as well. Some studies have reported that the $\mathrm{CH}$ stretching frequency of polymers in the FTIR spectrum will shift to lower frequencies due to of $\mathrm{CH}^{-}$ $\pi$ interactions. ${ }^{55}$ However, the FTIR spectrum recorded in this study does not exhibit shifts of the $\mathrm{CH}$ stretching frequency of the methine $(\nu \mathrm{CH})$, methylene $\left(\nu \mathrm{CH}_{2}\right)$, and methyl $\left(\nu \mathrm{CH}_{3}\right)$ groups of iPP. Unfortunately, the existence of $\mathrm{CH}-\pi$ interaction cannot be proved directly. However, the present experimental results clearly provide circumstantial evidence, implying the presence of $\mathrm{CH}-\pi$ interactions.

\section{Conclusions}

PP nanocomposites with small amounts of benzoic acidfunctionalized $\mathrm{Al}_{2} \mathrm{O}_{3}$ NPs were prepared by melt-mixing and were found to have greatly enhanced mechanical properties and crystallization behaviors. The tensile strength, flexural modulus, and impact strength were significantly increased in the iPP/BA- $\mathrm{Al}_{2} \mathrm{O}_{3}$ nanocomposites compared to those of the iPP/ $\mathrm{Al}_{2} \mathrm{O}_{3}$ nanocomposites and pristine iPP. According to the Einstein equation, the interfacial adhesion was estimated by the parameter $B$. The values of constant $B$ are much higher than 2.5, indicating that the interfacial adhesion is significantly strong.

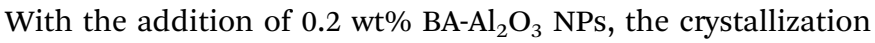
temperature remarkably increases by $14.8{ }^{\circ} \mathrm{C}$. Pristine $\mathrm{Al}_{2} \mathrm{O}_{3}$ only showed slight nucleation ability at the same content. Moreover, the crystallization rate of iPP significantly increased upon incorporating the $\mathrm{BA}-\mathrm{Al}_{2} \mathrm{O}_{3}$ NPs. Finally, the dynamic process of $\mathrm{BA}-\mathrm{Al}_{2} \mathrm{O}_{3}$-induced iPP crystallization was investigated 
at the molecular level using time-resolved FTIR measurements. The presence of $\mathrm{BA}-\mathrm{Al}_{2} \mathrm{O}_{3}$ facilitates the conformational ordering as well as the formation of long helical segments in the initial crystallization stage. It was supposed that the $\mathrm{CH}-\pi$ interaction between the protruding methyl groups of iPP and the benzene rings of $\mathrm{BA}-\mathrm{Al}_{2} \mathrm{O}_{3}$ accelerates the intrachain conformational ordering, which is accompanied by a considerable enhancement of the crystallization. Subsequently, the mechanical properties of the products also improved remarkably due to the interfacial interactions.

\section{Conflicts of interest}

There are no conflicts to declare.

\section{Acknowledgements}

The authors gratefully acknowledge the financial support for this study by National Natural Science Foundation of China (Grants 21476085 and 21606084), National Key R\&D Program of China (2016YFB0302201), and the Fundamental Research Funds for the Central Universities (222201717025).

\section{References}

1 Q. Wang, J. P. Undrell, Y. Gao, G. Cai, J. C. Buffet, C. A. Wilkie and D. O'Hare, Macromolecules, 2013, 46, 6145-6150.

2 G. Zhang, D. Brannum, D. Dong, L. Tang, E. Allahyarov, S. Tang, K. Kodweis, J. K. Lee and L. Zhu, Chem. Mater., 2016, 28, 4646-4660.

3 B. Wang, H. R. Zhang, C. Huang, L. Xiong, J. Luo and X. Chen, RSC Adv., 2017, 7, 42113-42122.

4 F. J. Medellín-Rodríguez, J. M. Mata-Padilla, B. S. Hsiao, M. A. Waldo-Mendoza, E. Ramírez-Vargas and S. SánchezValdes, Polym. Eng. Sci., 2007, 47, 1889-1897.

5 Z. Han and A. Fina, Prog. Polym. Sci., 2011, 36, 914-944.

6 J. Gong, R. Niu, X. Wen, H. Yang, J. Liu, X. Chen, Z. Y. Sun, E. Mijowska and T. Tang, RSC Adv., 2014, 5, 5484-5493.

7 P. Song, Z. Cao, Y. Cai, L. Zhao, Z. Fang and S. Fu, Polymer, 2011, 52, 4001-4010.

8 S. Yang, Y. Li, Y.-Y. Liang, W.-J. Wang, Y. Luo, J.-Z. Xu and Z.-M. Li, RSC Adv., 2016, 6, 23930-23941.

9 H. Zhao and R. K. Li, J. Polym. Sci., Part B: Polym. Phys., 2005, 43, 3652-3664.

10 B. Nagendra, K. Mohan and E. B. Gowd, ACS Appl. Mater. Interfaces, 2015, 7, 12399.

11 L. Qiu, Y. Gao, X. Yan, J. Guo, A. Umar, Z. Guo and Q. Wang, RSC Adv., 2015, 5, 51900-51911.

12 S. Mallakpour and E. Khadem, Prog. Polym. Sci., 2015, 51, 7493.

13 A. Khabibullin, K. Bhangaonkar, C. Mahoney, L. Zhao, M. Schmitt, A. K. Sekizkardes, M. R. Bockstaller and K. Matyjaszewski, ACS Appl. Mater. Interfaces, 2016, 8, 5458-5465.

14 M. Moniruzzaman and K. I. Winey, Macromolecules, 2006, 39, 5194-5205.
15 Y. Y. Liang, J. Z. Xu, X. Y. Liu, G. J. Zhong and Z. M. Li, Polymer, 2013, 54, 6479-6488.

16 N. Ning, S. Fu, W. Zhang, F. Chen, K. Wang, H. Deng, Q. Zhang and Q. Fu, Prog. Polym. Sci., 2012, 37, 1425-1455.

17 Z. Guo, T. Pereira, O. Choi, Y. Wang and H. T. Hahn, J. Mater. Chem., 2006, 16, 2800-2808.

18 S. Zhao, J. Zhang, S. Zhao, W. Li and H. Li, Compos. Sci. Technol., 2003, 63, 1009-1014.

19 M. Wåhlander, F. Nilsson, E. Larsson, W. C. Tsai, H. Hillborg, A. Carlmark, U. W. Gedde and E. Malmström, Polymer, 2014, 55, 2125-2138.

20 S. C. Cobo, M. Wåhlander, N. Taylor, L. Fogelström and E. Malmström, ACS Appl. Mater. Interfaces, 2015, 7, 25669.

21 B. Gu and A. Sen, Macromolecules, 2002, 35, 8913-8916.

22 D. Liu, A. M. Pourrahimi, R. T. Olsson, M. S. Hedenqvist and U. W. Gedde, Eur. Polym. J., 2015, 66, 67-77.

23 L. T. Truong, A. Larsen, B. Holme, F. K. Hansen and J. Roots, Polymer, 2011, 52, 1116-1123.

24 T. T. Le, Å. Larsen, B. Holme, S. Diplas, F. K. Hansen, J. Roots and S. Jørgensen, Surface \& Interface Analysis, 2010, 42, 10461049.

25 E. Pérez, V. Alvarez, C. J. Pérez and C. Bernal, Composites, Part B, 2013, 52, 72-83.

26 D. Pedrazzoli, V. Khumalo, J. Karger-Kocsis and A. Pegoretti, Polym. Test., 2014, 35, 92-100.

27 R. H. Ebengou, J. Polym. Sci., Part B: Polym. Phys., 2015, 35, 1333-1338.

28 T. L. Smith, D. Masilamani, K. B. Long, Y. P. Khanna, R. G. Bray, W. B. Hammond, S. Curran, J. J. Belles and S. Bindercastelli, Macromolecules, 1994, 27, 3147-3155.

29 M. R. Mani, R. Chellaswamy, Y. N. Marathe and V. K. Pillai, Chem. Commun., 2015, 51, 10026-10029.

30 R. Yang, L. Ding, W. Chen, L. Chen, X. Zhang and J. Li, Macromolecules, 2017, 50, 1610-1617.

31 W. Al-Shatty, A. M. Lord, S. Alexander and A. R. Barron, ACS Omega, 2017, 2, 2507-2514.

32 S. Alexander, J. Eastoe, A. M. Lord, F. Guittard and A. R. Barron, ACS Appl. Mater. Interfaces, 2015, 8, 660-666.

33 S. Anaya, B. Serrano, B. Herrero, A. Cervera and J. Baselga, ACS Appl. Mater. Interfaces, 2014, 6, 14460-14468.

34 C. H. Chen, C. F. Mao, M. S. Tsai, F. S. Yen, J. M. Lin, C. H. Tseng and H. Y. Chen, J. Appl. Polym. Sci., 2008, 110, 237-243.

35 J. Z. Xu, Y. Y. Liang, G. J. Zhong, H. L. Li, C. Chen, L. B. Li and Z. M. Li, J. Phys. Chem. Lett., 2012, 3, 530-535.

36 C. E. Bethley, C. L. Aitken, C. J. Harlan, Y. Koide, S. G. Bott and A. R. Barron, Organometallics, 1997, 16, 329-341.

37 N. Wu, L. Fu, M. Su, M. Aslam, K. C. Wong and V. P. Dravid, Nano Lett., 2004, 4, 383-386.

38 C. Shepherd, E. Hadzifejzovic, F. Shkal, K. Jurkschat, J. Moghal, E. M. Parker, M. Sawangphruk, D. R. Slocombe, J. S. Foord and M. G. Moloney, Langmuir, 2016, 32, 79177928.

39 F. Mammeri, E. L. Bourhis, L. Rozes and C. Sanchez, J. Mater. Chem., 2005, 15, 3787-3811.

40 L. Zhou, C. Gao and W. Xu, J. Mater. Chem., 2010, 20, 56755681. 
41 E. Roumeli, E. Pavlidou, A. Avgeropoulos, G. Vourlias, D. N. Bikiaris and K. Chrissafis, J. Phys. Chem. B, 2014, 118, 11341-11352.

42 S. Zhao, Z. Cai and Z. Xin, Polymer, 2008, 49, 2745-2754.

43 J. Wang, J. Yang, L. Deng, H. Fang, Y. Zhang and Z. Wang, ACS Appl. Mater. Interfaces, 2015, 7, 1364-1375.

44 J. D. Hoffman and R. L. Miller, Polymer, 1997, 38, 3151-3212. 45 Y. Cong, Z. Hong, Z. Qi, W. Zhou, H. Li, H. Liu, W. Chen, X. Wang and L. Li, Macromolecules, 2010, 43, 9859-9864.

46 G. Strobl, European Physical Journal E, 2000, 3, 165-183.

47 X. Zhu, D. Yan and Y. Fang, J. Phys. Chem. B, 2001, 105, 12461-12463.

48 Y. Geng, G. Wang, Y. Cong, L. Bai, L. Li and C. Yang, Macromolecules, 2009, 42, 4751-4757.
49 G. Parthasarthy, M. Sevegney and R. M. Kannan, J. Polym. Sci., Part B: Polym. Phys., 2002, 40, 2539-2551.

50 H. An, B. Zhao, Z. Ma, C. Shao, X. Wang, Y. Fang, L. Li and Z. Li, Macromolecules, 2007, 40, 4740-4743.

51 D. Baskaran, J. W. Mays and M. S. Bratcher, Chem. Mater., 2005, 17, 3389-3397.

52 A. Beigbeder, M. Linares, M. Devalckenaere, P. Degée, M. Claes, D. Beljonne, R. Lazzaroni and P. Dubois, Adv. Mater., 2008, 20, 1003-1007.

53 T. Yamate, K. Kumazawa, H. Suzuki and M. Akazome, ACS Macro Lett., 2016, 5, 858-861.

54 K. Lu, N. Grossiord, C. E. Koning, H. E. Miltner, B. v. Mele and J. Loos, Macromolecules, 2008, 41, 8081-8085.

55 T. Iwamura, K. Adachi and Y. Chujo, Polym. J., 2004, 36, 871877. 